\title{
La relación entre gramática y pensamiento en la Gramática de Port Royal: un contraste con la Minerva de Francisco Sánchez
}

\author{
Teresa ÁLVAREZ MATEOS ${ }^{\mathrm{i}}$ \\ Albert-Ludwig Universität Freiburg \\ Universidad Nacional de Educación a Distancia
}

\begin{abstract}
RESUMEN
En relación polémica con la señalada continuidad entre la Gramática de Port-Royal y la Minerva de Francisco Sánchez, y de ambas respecto de los desarrollos recientes de la Lingüística, este ensayo pretende profundizar en las diferencias entre estos enfoques, atendiendo en especial al particular modo de entender las relaciones entre gramática y pensamiento en las obras de Francisco Sánchez y Port-Royal.
\end{abstract}

PALABRAS CLAVE: Port Royal, Francisco Sánchez, gramática, lingüistica, significado

\begin{abstract}
In a problematic relationship with the noted continuity between Port-Royal's Grammar and Francisco Sánchez's Minerva, and with both regarding the recent developments in Linguistics, this essay tries to go into detail about the differences between these approaches, and specially about the relations between grammar and thought in Sánchez and Port Royal's works.
\end{abstract}

KEYWORDS: Port Royal, Francisco Sánchez, grammar, linguistics, meaning

Desde la publicación de la obra de Noam Chomsky Cartesian Linguistics: A Chapter in the History of Rationalist Thought (1966), se multiplicaron los estudios dedicados a buscar las raíces de las ideas lingüísticas propias de la gramática generativa en autores anteriores al nacimiento de la lingüística como cienciaii, que desarrollaron sus análisis acerca del lenguaje en el marco de la disciplina tradicional de la gramática. El principal hilo conductor para esta reconstrucción de los antecedentes de la lingüística realizada por Chomsky, fue la distinción entre estructura profunda y estructura superficial del lenguaje, desarrollada en su obra Aspects of the Theory of Syntax (1965), según la cual el componente sintáctico de la gramática interrelaciona y especifica la interpretación semántica de cada construcción lingüística, es decir, su estructura profunda, y su interpretación fonética o estructura superficial. La estructura profunda está constituida por un esquema sintáctico o marcador de frase -por ejemplo uno de la forma Sintagma Nominal (SN)- Modificador (Aux)- Sintagma Verbal (SV)-, el cual especifica tanto las subdivisiones categoriales que pueden desplegarse a partir de este esquema, como el conjunto de rasgos semánticos que definen un conjunto dentro del léxico admisible para la realización de determinadas 
funciones. La estructura superficial resulta, a su vez, de la aplicación de una serie de reglas de transformación sobre la base de la estructura profunda. El marcador de transformación de la estructura profunda contiene así la base para su modificación y para la génesis de la estructura superficial.

Chomsky afirma encontrar en la Gramática general de Port-Royal un antecedente claro de esta distinción entre estructura profunda y estructura superficial: «Since the origins of this work in the Grammaire générale et raisonnée, it has been emphasized that the deep structures for which universality is claimed may be quite distinct from the surface structures of sentences as they actually appear» ${ }^{1}$. El planteamiento cartesiano presente en las ideas de Port-Royal determinaría, de este modo, una concepción dualista del lenguaje, conforme a la cual la doble dimensión corpórea y espiritual del signo lingüístico permite que se pueda considerar una frase tanto desde el punto de vista de su apariencia física, como atendiendo al modo en que la frase expresa un pensamiento. Si en el nivel semántico, la organización del significado puede reducirse a la forma lógica del pensamiento, considerada como única y válida para todas los lenguajes naturales existentes, el reconocimiento de la disociación entre estos dos niveles explica el carácter no necesario de la correspondencia entre la organización de los contenidos en el nivel semántico y su expresión efectiva en la frase. Los diferentes procesos de transformación que determinan el paso al nivel superficial, explican tanto las diferencias entre los diferentes lenguajes naturales, como las expresiones del resto de "operaciones del espíritu", a saber, las interrogaciones, las órdenes y otras formas de expresión y figuras retóricas que modifican la forma lógica del pensamiento. En una de las notas añadidas como comentario al capítulo dedicado a la estructura profunda y la estructura superficial en la Lingüistica cartesiana iii leemos: «Aparte de sus orígenes cartesianos, la teoría del lenguaje de Port-Royal, con su distinción entre la estructura profunda y superficial, se puede llevar hasta la gramática escolástica y la renacentista; en particular hasta la teoría de la elipsis y de los "tipos ideales" que alcanzaron su más pleno desarrollo en la Minerva de

\footnotetext{
${ }^{1}$ N. CHOMsky, Aspects of the Theory of Syntax. Cambridge M.A., The M.I.T. Press, 118. La continuidad de la teoría chomskiana con la obra de Port-Royal se expresa con mayor rotundidad en Lingüística cartesiana: «En muchos aspectos me parece muy preciso, pues, considerar la teoría de la gramática generativa transformacional, según se está elaborando en la actualidad, como una versión esencialmente moderna y más explícita de la teoría de Port-Royal» (N. CHOMSKY, Lingüística cartesiana. Un capitulo de la historia del pensamiento racionalista. Madrid, Gredos, 1972, 88).
} 
Sanctius» ${ }^{2}$. Chomsky distingue entre la naturaleza psicológica de la distinción entre estructura profunda y superficial en Port-Royal, frente a su funcionalidad meramente instrumental para encontrar soluciones explicativas a formas lingüísticas dadas dentro del análisis de textos en estos tratados de retórica escolásticos y renacentistas. Las críticas ulteriores a la consideración de Chomsky de la Gramática de Port-Royal como el principal exponente de la "lingüística cartesiana" van desde la negación de la influencia del pensamiento de Descartes en esta obra (Stéfanini, 1959) a la restricción y limitación de esta influencia ante el mayor peso de las ideas lingüísticas propias de los gramáticos que precedieron a Arnauld y Lancelot, especialmente el autor de la Minerva (Lakoff, 1969)33. La atención a la obra de Francisco Sánchez como antecedente de las ideas de Port-Royal da lugar a una segunda interpretación en el marco de la Historia de la Lingüística: la consideración de la Minerva como una anticipación de la gramática generativa $^{\text {iv }}$. La distinción que realiza Francisco Sánchez entre las figuras de pensamiento y las figuras de palabras, de tal manera que solo estas últimas se ven alteradas por la paráfrasis, daría cuenta también de la distinción entre estructura profunda o nivel semántico subyacente a la expresión, y estructura superficial manifiesta, no en el nivel fonológico, sino en el estrictamente textual. La posibilidad del funcionamiento de un recurso gramatical como la elipsis y su recuperación por medio de la catálisis se explican por la existencia de un nivel semántico anterior a las transformaciones que se producen en el plano de la expresión.

El objetivo de este ensayo consistirá en contrastar el enfoque gramatical de la Minerva con las ideas de Port-Royal, a fin de cuestionar los paralelismos establecidos entre ambas obras que surgieron a partir de los trabajos sobre Historia de la Lingüística, a causa de la consideración de ambos tratados de gramática como posibles antecedentes de la

\footnotetext{
${ }^{2}$ N. Chomsky, Lingüistica cartesiana. Un capitulo de la historia del pensamiento racionalista. Madrid, Gredos, 1972, 79. Nota 67.

${ }^{3}$ «I think it fairly evident that the LINGUISTIC concepts, as opposed to the philosophical-psychological ones, do not originate with Descartes, but rather from some other source. I also note in passing that, although Cartesian philosophy was undoubtedly an influence on Lancelot and Arnauld in their writing of the GGR, as well as in their coming to hold the ideas of language exemplified in the GGR, the actual form of their theory originated in other sources developed before Descartes was born. Descartes, I would say, created in L \& A a favourable mental climate for them to accept these linguistic ideas». R. LAKOFF, Reviewed Work: Grammaire générale et raisonnée by C. Lancelot, A. Arnauld, Language Vol. 45, No. 2, Part 1 (Jun., 1969), 343-364.
} 
gramática generativa. Para ello analizaremos, en primer lugar, la concepción de la gramática propia de Francisco Sánchez y de los autores de Port- Royal, prestando atención al modo en que es comprendida en cada caso la relación entre la gramática y el pensamiento. Se analizará cuál es el criterio de corrección gramatical considerado por estos autores y la función y características que atribuyen respectivamente al lenguaje humano. En segundo lugar, analizaremos el carácter lógico que subyace a la comprensión de la oración según Port-Royal y lo diferenciaremos respecto de la estructura fundamental de la oración en Minerva. Atenderemos particularmente a la presentación de los pronombres personales en la Gramática de Port-Royal y en especial al papel que desempeña el pronombre de primera persona. Con ello valoraremos la influencia de la filosofía cartesiana en estos autores. Finalmente, reflexionaremos sobre el carácter de anomalías o recursos gramaticales expresivos que poseen en uno y otro caso las figuras retóricas. De esta forma constataremos la disolución de las fronteras entre gramática y filosofía que se efectúa en la obra de Port-Royal y la diferenciaremos respecto de la definición de la gramática como arte o técnica - ajena en todo caso a la pregunta acerca del significado - presente en la obra del Brocense.

\section{Hacia una nueva definición de la Gramática y de las relaciones entre el lenguaje y el pensamiento}

En el prefacio a la Gramática general y razonada (1660) Arnauld y Lancelot definen la gramática como el "arte de hablar" (l'art de parler), es decir, el modo por el cual los hombres expresan sus pensamientos a través de determinados signos. La gramática es así definida, por un lado, como la técnica de construcción de un discurso acorde con el pensamiento y, por otro, como la vía de conocimiento de los mecanismos recónditos del pensamiento. Por ello la gramática es el saber fundamental, que debe permanecer como base de todas las ciencias. Los autores de Port-Royal conciben el lenguaje original y esencialmente como un lenguaje oral, y por ello toman como los primeros signos del lenguaje los sonidos que el hombre puede producir dentro de un conjunto finito de unidades disponibles. Dado que los signos desaparecen con el paso del tiempo, se necesitan otros símbolos que conviertan a los primeros en visibles y duraderos, es decir los caracteres de la escritura, los $\gamma \varrho \dot{\alpha} \mu \mu \alpha$, a partir de los cuales se funda el nombre de la 
gramáticav. Esta primera consideración señala ya la siguiente tendencia por parte de los autores de Port-Royal: consideran como signos primarios los sonidos articulados, aquellos capaces de construir un discurso, es decir, los sonidos capaces de ser partes de palabras. Por el contrario, otros ruidos y gestos no participarían en la construcción del discurso y ello explica la limitada atención a las interjecciones en la gramática general: estas señalan solo los movimientos del espíritu y son antes naturales que artificialesvi. El objeto de la gramática es, por consiguiente, el resultado de la estabilización del lenguaje oral: analiza un producto artificial, que permite la conservación del habla. Puesto que los signos son la expresión del pensamiento, podemos reconocer en ellos dos partes: la primera atañe a la naturaleza material del signo, que puede ser un sonido o un carácter escrito, la segunda afecta al significado, que es expresión del pensamiento. Esta segunda parte sería específica del hombre frente a la producción de sonidos materiales, la cual es una actividad compartida con los animales que el hombre modifica radicalmente por medio de la articulación de palabras en un discurso acorde al pensamiento. Aunque solo los sonidos designan de manera inmediata el pensamiento, y la escritura de manera mediata, con frecuencia los hombres pueden pensar de manera directa - es decir, sin traducción a los sonidos- en un objeto por medio de la escritura.

En coincidencia con otros autores del siglo XVII como Locke y Hobbes, los lógicos de Port-Royal consideran la unión de determinados pensamientos con secuencias de sonidos como el resultado de una convención: " parler est expliquer ses pensées par des signes que les hommes ont inventés à ce dessein ». En este sentido Foucault presenta en Las palabras y las cosas las dos caras del signo como el contraste entre, por un lado, lo individual y natural -es decir, los pensamientos- y, por otro, lo arbitrario y general- los tonos y caracteres materiales. En el contexto del siglo XVII lo natural significa para Foucault la espontaneidad de los pensamientos inmediatos en contraposición al artificio del lenguaje de palabras. Con ello se añade un nuevo atributo del rol de la gramática en la investigación de las relaciones entre lenguaje y pensamiento: el lenguaje sirve como medio para el conocimiento de los pensamientos, en la medida en la que estos ya han adoptado un código convencional construido de acuerdo con reglas. ¿Cómo entender aquí la contraposición entre naturaleza y convención? ¿Es un correlato de la contraposición entre el dominio de los instintos y las instituciones humanas libremente elegidas? 
Los signos serán analizados en primer lugar atendiendo a su materia, comenzando desde los elementos más simples, que generan elementos superiores por combinación: vocales (secundariamente consonantes), sílabas, palabras y oraciones. La búsqueda de los elementos más simples va unida, además, a la contraposición entre representaciones claras o confusas: se considerarán elementos más simples aquellos que puedan expresar un pensamiento. La consideración del "elemento simple" es entonces problemática: se considera en el orden material lo simple como punto de partida, siempre y cuando por eso simple se designe a la unidad mínima sin significado que en contraposición con otras unidades consideradas superfluas permita constituir una unidad superior, la oración, que permita, ahora sí, designar las unidades simples de pensamiento. Los gramáticos de PortRoyal consideran que la articulación del lenguaje en estos tres niveles, fonológico, morfológico y sintáctico, es un aspecto común a todas las lenguas naturales, concluyendo por tanto que la oración es la estructura lingüística universal que permite la expresión del pensamiento. Si el objeto de estudio del que parte la gramática general es la lengua francesa, la búsqueda de la estructura lingüística común motiva la comparación con otras lenguas romances, latín, griego y hebreo.

La novedad de la gramática de Port Royal y su relevancia como paradigma de las consideraciones modernas acerca del lenguaje es notable si lo comparamos con los tratados de gramática del siglo XVI. Tras la gran difusión de la primera gramática de la lengua española a cargo de Antonio de Nebrija (1492), Francisco Sánchez publica en 1587 la Minerva o de causis linguae latinae, donde ofrece una gramática para el latín. En una época en que el uso de la lengua española ya ha sido fijado y regulado, la obra de Francisco Sánchez obedece a la tendencia del Renacimiento, en la medida en que retorna a consideraciones del lenguaje propias de la Antigüedad, para establecer las reglas que han de fijar el latín clásico. Su defensa de la pureza de la lengua latina frente a las derivaciones de las lenguas romances funcionará, sin embargo, como motor para la modernización en la consideración sistemática del lenguaje. En diálogo con la obra de Nebrija, Francisco Sánchez considera la gramática como el saber fundamental que está a la base del desarrollo de la ciencia. Sin embargo, su comprensión de cuál sea el fundamento racional de la gramática se aleja radicalmente de las consideraciones de la Gramática general. Sus consideraciones acerca de la posibilidad de un espíritu humano universal subyacente bajo la diversidad de las lenguas concretas, dependen de la 
consideración de una lengua originaria, para cuya caracterización tomará como partida el relato bíblico del Génesis. En la Minerva se expone el origen del lenguaje a través del acto por el cual Adán concede los nombres a las criaturas. La situación originaria no es por tanto la transmisión de pensamientos innatos a un interlocutor, sino la elección del nombre adecuado para las cosas externas. Francisco Sánchez coincide, por un lado, con la idea defendida por el personaje de Crátilo en el diálogo platónico, acerca de la unión natural entre las palabras y las cosas nombradas, en la medida en que la primera lengua describe el orden natural, pero por otro lado asume la perspectiva convencionalista, en la medida en la que la elección de los nombres es una acción motivada. Rechaza aquellas interpretaciones de la tesis convencionalista aristotélica, que juzgan el convencionalismo como un hecho causal o arbitrario. La unión natural originaria entre las palabras y las cosas es el fundamento para la búsqueda de las causas de los fenómenos gramaticales: los nombres son como los instrumentos y las marcas de las cosas, y cada instrumento de una técnica se adecúa a esta técnica, volviéndose inútil para todas las demás. A través de la repetición y el hábito los nombres quedan fijados a las cosas, y por ello la investigación de la razón subyacente al uso de una palabra implica el análisis histórico de su etimología. Las palabras serán consideradas como partes materiales del mundo, que pueden ser localizadas en los documentos escritos. Así, el análisis del significado racional de una palabra consiste en la indagación de los ejemplos disponibles en los cuales aparece una palabra, o aquellas otras palabras de las que esta deriva. Francisco Sánchez usa por tanto un método inductivo, realizando a partir de los datos generalizaciones con valor normativo. El método de Minerva coincide en diversos aspectos con la metodología propuesta por Francis Bacon, quien en el Novum Organum propone la recopilación de datos empíricos acerca de la regularidad de los fenómenos, y su clasificación en tablas de presencia o efectiva aparición del fenómeno, ausencia, o de diferencias graduales en caso de que la aparición del fenómeno sea irregular. Pero si el método de Bacon persigue la selección, generalización y previsión del grado de probabilidad de los fenómenos, Francisco Sánchez busca, por el contrario, la explicación racional de los casos excepcionales, considerando las causas que pueden alejar a determinado ejemplar de la norma. La racionalidad significa en este contexto cierta adecuación entre las palabras y las cosas, pero tal que la referencia de una palabra remite a otras palabras, tal que la racionalidad del lenguaje se apoya en la trabazón entre palabras. 
La pregunta acerca de las diferentes nomenclaturas de las cosas en los distintos idiomas puede explicarse atendiendo a la pluralidad de causas de una cosa, de manera que en cada lenguaje se expresa una causa determinada: «asi los griegos pusieron por nombre ánemos, los latinos uentum, los unos a partir de soplar, los otros a partir de uenio venin» ${ }^{4}$. Francisco Sánchez se refiere de un modo peculiar a la teoría platónica de la participación: porque un mismo objeto puede ser nombrado en relación a diferentes atributos, cada lengua acentuará uno de los mismos vii. Las diferentes nomenclaturas participan de la idea correspondiente al objeto, de manera que muestran una trabazón de diferentes significados. Francisco Sánchez afirma así la existencia de un lenguaje originario, al cual conducirían las lenguas naturales, y el cual serviría de guía para orientar el análisis etimológico. En este lenguaje originario habría una correspondencia exacta y unívoca entre las palabras y las cosas. Este nivel de correspondencia fundamenta la división de la gramática en la Minerva: contra la división de la gramática en ortografía, prosodia, etimología y sintaxis en la Gramática de Nebrija, Francisco Sánchez solo atenderá en un primer momento al análisis de los miembros de la frase y de sus funciones sintácticas. La atención al latín justifica la primacía de la lengua escrita, y de nuevo el alejamiento respecto de Port-Royal, quienes encuentran en la fonología la primera articulación del lenguaje. Si podemos conceder, con Foucault, que la Minerva de Francisco Sánchez se adecúa a la típica forma de pensamiento del Renacimiento conforme a la semejanza y la analogía, la atención a la remisión de unas palabras a otras y la comparación entre las fuentes disponibles supone que la costumbre en el uso del lenguaje obedece a cierta racionalidad. Así, lo característico de la fijación de las reglas correctas de la gramática no es meramente la fijación de las regularidades y semejanzas en el uso de una palabra, sino la observación de los mecanismos que rigen la técnica de la sintaxis, tales como la concordancia en género y número, o el régimen, es decir, la exigencia de determinado caso. Puesto que Francisco Sánchez concede que la pregunta acerca del significado, el ámbito de la semántica en la lingüística contemporánea, es en realidad una tarea de los filósofos en lugar de los gramáticos, el ámbito de la gramática permanece dentro de las fronteras del uso documentado de las palabras en las lenguas naturales. La idea de una lengua originaria es entonces para el gramático una hipótesis funcional, que cae fuera de su ámbito de estudio.

\footnotetext{
${ }^{4}$ F. SÁNCHEZ DE LAS BROZAS, Minerva o de causis linguae latinae. Edición bilingüe, Cáceres, Institución cultural el Brocense, 1995, 41.
} 
Por el contrario, para los autores de Port-Royal la investigación de la gramática coincide con la pregunta acerca del significado y, por ello, la estructura fundamental de la oración es puesta en conexión con la estructura lógica de la proposición.

\section{La estructura fundamental de la oración: reducción a la estructura fundamental del juicio}

Francisco Sánchez cancela las consideraciones de la ortografía y de la prosodia con un argumento doble: por un lado la gramática no se deja considerar como el conjunto de estos ámbitos separados, porque la parte de una cosa no puede ser al mismo tiempo parte de otra: «la letra es parte de la sílaba, la sílaba de la palabra y las palabras partes de la propia oración, luego no son parte de la gramática: la parte de cualquier cosa no puede ser parte de otra» ${ }^{5}$. Por otro lado la sintaxis es el objetivo de la gramática, de manera que no puede ser una parte de ella. De este modo distingue el autor entre los contenidos de la gramática y la forma dada a estos contenidos. A causa de la hipótesis del lenguaje originario, Francisco Sánchez presupone que los nombres son los materiales primeramente disponibles para el gramático, son la sustancia del lenguaje. La distinción de las letras dentro del nombre sólo sería una tarea de despiece de estas sustancias registradas. Este planteamiento conduce a la distinción de los elementos de la oración en tres categorías esenciales, a saber los nombres, los verbos y las partículas. Como los autores de Port-Royal, deja a un lado las interjecciones - a causa, en este caso, de su no pertenencia a la frase- y también los pronombres, por tener una función sustitutoria. La categoría de nombre incluye tanto al sustantivo como al adjetivo, como quiera que el sustantivo determina las condiciones para la concordancia con el adjetivo. Frente al reconocimiento de hasta ocho categorías gramaticales que encontramos en Nebrija, Francisco Sánchez, apelando a las distinciones gramaticales documentadas de los hebreos, de los árabes, de Plutarco, San Agustín y Aristóteles, reconoce estos tres elementos en la frase. Citando El Sofista de Platón en relación al carácter temporal o permanente de aquello de lo que se habla, concluye que el nombre es la marca para las cosas que permanecen, el verbo la marca para las cosas temporales que solo tienen lugar mientras duran, y la categoría de partícula comprende el modo que tiñe el significado de

\footnotetext{
${ }^{5}$ F. SÁNCHEZ DE LAS BROZAS, Minerva o de causis linguae latinae, 47.
} 
los nombres y de los verbos, aclarando así la razón de las cosas. Los verbos dan la forma a los nombres, los cuales constituyen la materia del lenguaje. Porque Francisco Sánchez considera la investigación de la unión entre las palabras y las cosas como objeto de la filosofía, aporta otra definición de los nombres de carácter sintáctico, más adecuada a la gramática: «El nombre es el género cuyas especies son el número, el género y el caso» ${ }^{6}$ y el verbo «la palabra que tiene número, persona y tiempo»7viii. Las diferencias entre una definición gramatical y una definición filosófica son claras en el caso de las partículas: el gramático solo debe atender a las conjunciones y adverbios en relación a sus funciones sintácticas, analizándolas por ejemplo como conectores o modificadores de los verbos, con independencia de los significados determinados que puedan aportar (determinaciones de lugar, temporales, de negación, etc.). Pero esta separación no es tan clara en el caso de los nombres y verbos, esto es, de los miembros que por sí solos pueden formar una frase con significado pleno. De hecho, la función sintáctica de los nombres y de los verbos se fundamenta en determinados supuestos ontológicos: para que el nombre pueda funcionar como sujeto de la oración, tiene que designar en principio una sustancia, y para que el verbo pueda funcionar como un predicado, ha de designar o bien una acción o bien una pasión ${ }^{i x}$ : «La filosofía, es decir, la argumentación cierta y sin error, no acepta ningún estado intermedio entre la acción y la pasión, porque cada movimiento es o bien activo o bien pasivo. Considerándolo de cerca la acción y la pasión sólo se diferencian en relación a determinada perspectiva del espíritu, como la diferencia entre subir y bajar» ${ }^{8}$. Como el verbo por sí solo no permite generar una unidad gramaticalmente completa, hay que lograr el nombre mentado bien sea deduciéndolo a partir de las terminaciones gramaticales del verbo, bien sea deduciéndolo del contexto. La suposición de un sujeto ausente es una de las bases de la teoría de la elipsis de Francisco Sánchez, expuesta, como veremos, en la tercera parte de la Minerva.

Esta concepción de la estructura principal de la oración se diferencia sustancialmente de aquella que aparece en la gramática de Port-Royal. Si bien observamos anteriormente que la selección de las unidades mínimas del lenguaje obedece a la búsqueda de elementos que, combinados entre sí, dan lugar a estructuras (oraciones)

\footnotetext{
${ }^{6}$ F. SÁNCHEZ DE LAS BROZAS, Minerva o de causis linguae latinae, 61.

${ }^{7}$ F. SÁNCHEZ DE LAS BROZAS, Minerva o de causis linguae latinae, 85.

${ }^{8}$ F. SÁNCHEZ DE LAS BROZAS, Minerva o de causis linguae latinae, 235.
} 
susceptibles de expresar pensamientos, hay otro aspecto de la consideración del nivel fonológico como punto de partida que conviene destacar: su papel para dar cuenta de la universalidad del lenguaje humano. Los fonemas concretos de un lenguaje pueden considerarse como realizaciones particulares de un conjunto general de sonidos realizables por el hombre. La universalidad de la materia del lenguaje se funda así en la posibilidad de una base fonológica común. Arnauld y Lancelot registran en la primera parte de la Gramática la configuración de la materia de las lenguas modernas por medio de un método puramente descriptivo, que ofrece un inventario de los diferentes sistemas vocálicos y consonánticos. De este modo puede observarse la distancia entre las clasificaciones de Port-Royal y la comprensión sistemática de la fonología en las posteriores ciencias del lenguaje: a pesar de la consideración de estos autores como precedente de la lingüística moderna, Arnauld y Lancelot no investigan ni las leyes del desarrollo de los fonemas en las lenguas indoeuropeas, como los neogramáticos alemanes ${ }^{9}$, ni las relaciones de oposición y contraste entre los fonemas de un sistema, como en el caso de la lingüística estructuralista. En cualquier caso, las clasificaciones de Port-Royal avivan el interés para el análisis comparativo de las lenguas indoeuropeas, aportando una gran cantidad de materiales que puedan facilitar posteriores investigaciones sistemáticas.

La consideración de los sonidos como el primer elemento para la construcción de la gramática muestra la atención al cuerpo humano como una fábrica de expresiones verbales convencionales. Los sonidos articulados de este modo son instrumentos, que sirven para la expresión del espiritu humano. No se trata en este caso de que los verbos animen y den forma a la sustancia de los nombres: la organización de las unidades materiales comienza con la acción del espíritu sobre los movimientos producidos en el cuerpo humano. La relación de la palabra con aquello que es inmediatamente pensado señala el punto de partida de los autores de Port-Royal acerca de las relaciones entre las palabras y las cosas. En alusión a la definición agustiniana del signo en De Doctrina Christiana, Pierre Nicole considera el signo como aquella cosa que puede ser empleada para designar alguna otra, pero lo designado no es concebido como una realidad exterior, sino como una representación. Si para San Agustín los signos despiertan en nuestra mente el pensamiento de alguna otra $\cos a^{\mathrm{x}}$, vemos en el planteamiento de Port-Royal una

${ }^{9}$ Cfr. J. ČERnÝ, Historia de la lingüistica, Universidad de Extremadura, 1998. 
teoría de la referencia dualista de la forma "signo-representación" que suspende temporalmente la relación con la exterioridadxi. La suspensión de la referencia a las cosas externas acompaña al reconocimiento del carácter artificial del signo: los signos no son "partes" del mundo, o cosas singulares entre el resto de cosas, que aguarden el descubrimiento del lector. Por el contrario mantienen una relación cognitiva inmediata con el espíritu. Esta disponibilidad de los pensamientos para la conciencia motiva la explicación del origen de los pronombres personales según Port-Royal: puesto que cada acto de comunicación oral comienza con la exteriorización de los pensamientos inmediatos, "yo" constituye la primera forma pronominal. En segundo lugar se desarrolla la segunda persona, a causa de la necesidad de comunicar estos pensamientos. Finalmente aparece la tercera persona a través de la referencia al resto de personas y cosas que rodean a los participantes en el diálogo. La comprensión del lenguaje como medio del pensamiento implica que aquello que es inmediato solo puede ser aprehendido por medio del conocimiento del mensaje expresado.

Volviendo de nuevo al texto del segundo libro de Minerva observamos cómo Francisco Sánchez considera que el verbo y el nombre solo concuerdan en cuanto al número: «Se objetará que en la oración ego docet hay concordancia en cuanto al número aunque la oración no parezca coherente» ${ }^{10}$. Francisco Sánchez responde a esta crítica considerando las oraciones del tipo ego docet como una excepción de la regla: el nominativo siempre ha de estar en tercera persona a excepción de las formas yo y tú. La base para ello sigue los requisitos de la sintaxis: la persona es la categoría gramatical que modifica la forma de la palabra a la que afecta. Puesto que no hallamos cambios en los nombres en relación a la persona gramaticalxii, se concluye que la persona es exclusivamente una categoría del verbo. La expresión aparentemente contradictoria acerca de que el nominativo siempre aparece en la tercera persona puede ser explicada si tomamos la tercera persona como una neutralización de la diferenciación de personas gramaticales. Así encontramos en la Minerva un planteamiento del uso de los pronombres personales distinto al que encontramos en Port-Royal: la primera persona no es la fuente de la comunicación lingüística, sino uno de los posibles actores o receptores pasivos de la acción del verbo. En este sentido podemos comprender la innovación de la Gramática de Port-Royal como

${ }^{10}$ F. SÁNCHEZ DE LAS BROZAS, Minerva o de causis linguae latinae, 125. 
un ejercicio de abstracción en relación a la comprensión tradicional de las relaciones entre sujeto y predicado. El papel fundamental del "yo", portador de pensamientos inmediatos, como fuente de la producción del lenguaje muestra la influencia de la filosofía cartesiana en los autores de Port-Royal. El reconocimiento del carácter inmediato del pensamiento refleja el empleo del método cartesiano de la reducción de la certeza en relación al conocimiento del mundo externo con el consiguiente retorno a los contenidos de conciencia más simples y evidentes:

Pero advertí luego que, queriendo yo pensar, de esa suerte, que todo es falso, era necesario que yo, que lo pensaba, fuese alguna cosa; y observando que esta verdad: "yo pienso, luego soy", era tan firme y segura que las más extravagantes suposiciones de los escépticos no son capaces de conmoverla, juzgué que podía recibirla, sin escrúpulo, como el primer principio de la filosofía que andaba buscando ${ }^{11}$.

La conciencia aparece como un campo indubitable y con ello como el punto de partida adecuado para alcanzar un conocimiento cierto. Recordaremos el conocido pasaje de la tercera de las Reglas para la dirección del espiritu12:

Entiendo por intuición, no la creencia en el variable testimonio de los sentidos o en los juicios engañosos de la imaginación - mala reguladora - sino la concepción de un espíritu sano y atento, tan distinta y fácil que ninguna duda quede sobre lo conocido; o lo que es lo mismo, la concepción firme que nace en un espíritu sano y atento, por las luces naturales de la razón.

Este fragmento nos lleva a replantear la pregunta anterior acerca de la contraposición entre naturaleza y convención. En cierto sentido ya ha sido anticipado en la consideración de los tonos articulados como materia del lenguaje: ni Descartes ni los gramáticos de Port-Royal toman el instinto como fundamento de la luz, natural. En la mencionada contraposición entre naturaleza e institución, entienden como naturaleza la "naturaleza humana", la cual es candidata para la producción de instituciones. De este modo se puede explicar la posible identidad entre la expresión verbal y los pensamientos

11 R. DesCartes, Discurso del Método. IV. Madrid, Espasa Calpe, 1993, 68.

12 R. DESCARTES, Reglas para la dirección del espiritu. Madrid, Alianza Editorial, 1989, 75. 
inmediatos, siendo esta expresión tan solo el despliegue de lo que ya está dado de manera inmediataxiii. Permanece no obstante la pregunta acerca de la necesidad del despliegue de los pensamientos en un orden lineal. La expresión oral de los pensamientos permite su ordenación en una secuencia lineal. Por medio de este despliegue es posible hacer una comparación entre elementos separados: la expresión permite la comprensión de los pensamientos de acuerdo con identidades y diferencias. Este método se muestra, a causa de la distancia de los estados de cosas y del receptor, como necesario para alcanzar el reconocimiento de los pensamientos innatos del hablante. Solo gracias a la repetición de la aparición del objeto se puede concluir la identidad del objeto con la recopilación de sus sucesivos cambios. Esta comparación depende de la actividad del espíritu, que recuerda los sucesivos cambios e identifica la identidad que permanece, permitiendo la reconstrucción del todo. El espíritu se comporta así como creador de la identidad. El proyecto de una filosofía, que se concibe como método para alcanzar la forma correcta del pensamiento, encuentra en la inmediatez de la existencia del yo la demostración de la posibilidad de un saber cierto e indubitable frente a las variaciones de los sentidos. El espíritu es el actor del acto de concebir, es decir de la mirada intelectual del espíritu a las cosas. Este acto significa la base para el juicio, con el que se afirma de un objeto ya existente que es. La gramática de Port-Royal considera el juicio como el segundo acto del espíritu, que determina la estructura principal de la oración. Así, cada oración gramaticalmente correcta se puede reducir a una oración de la forma sujeto-atributo.

Podemos considerar esta propuesta como una gran transformación radical en relación a la concepción de la oración que leemos en Minerva. Por un lado, el verbo ya no es la expresión del tiempo en la oración, o la marca de la actividad o pasividad del sujeto, sino el nexo o cópula entre el sujeto y sus atributos. Cada oración predicativa se deja reducir a una oración copulativa. El objetivo del lenguaje no consistiría en la narración de acciones, en la escritura de la historia, sino en el acto reflexivo del juicio, que permite obtener una proposición verificable. El objetivo del juicio es la transferencia de la evidencia del yo a los objetos percibidos a través de la construcción de una afirmación, cuya verdad pueda ser demostrada por medio de la confrontación con los estados de cosas dados. La extensión del juicio en el tiempo, que se diferencia del acto espontáneo de concebir, permite la separación y unión entre dos elementos, sujeto y atributo, que a raíz de su separación permiten ser identificados. La actividad lingüística permite una 
comprobación de la identidad por parte del hablante y el receptor, y de este modo la convención, entendida como fundamento del lenguaje, significa la creación de un mundo compartido, en el que los estados de cosas permiten alcanzar un significado estable y común. La desconexión de la referencia en relación a los estados de cosas es, en consecuencia, un momento provisional del método que permite la construcción de un discurso verificable.

Por otro lado, el sujeto ya no será concebido como el actor o receptor de la acción del verbo. Si bien según Port-Royal los nombres son signos de las cosas, estas cosas ya no son la materia a la que el verbo da forma, sino el objeto de una definición. El juicio acerca del significado de una palabra implica la añadidura de atributos, es decir, de signos para la modificación de las cosas. El nombre del sujeto no tiene ningún significado con independencia de este recuento de atributos, puesto que el mero acto de concebir no requiere de ninguna expresión. Por ello, la palabra que cumple la función de sujeto será un signo, que continuamente remita a los signos concomitantes, en la búsqueda de la identidad entre las sucesivas modificaciones y el soporte vacío del sujeto. El orden de las palabras en una secuencia lineal responde ahora a una jerarquía sintáctica: el sujeto, es decir, aquello que es nombrado en primer lugar, determina la extensión del atributo, es decir el conjunto de objetos susceptibles de recibir esa modificación. Aunque como partes de una identidad el sujeto y el atributo podrían resultar intercambiables, el orden de la proposición determina aquella parte que es objeto de la definición. De este modo la Gramática sienta las condiciones para el uso del lenguaje, cuyo objetivo es la argumentación (raisonner), es decir la extensión del juicio por medio del continuo encadenamiento de identidades.

\section{La desaparición de las figuras retóricas del ámbito gramatical}

La perspectiva gramatical anterior implica la reducción de todos los actos de habla a la aserción: las oraciones afirmativas y negativas son medios de comunicación de proposiciones. Esta reducción acarrea una doble consecuencia:

- Por un lado, la confusión de las fronteras entre la gramática y la filosofía, si la pregunta sobre la esencia de las cosas se transforma en la construcción de las reglas para su definición. Contrariamente al tratado de Sanctius los autores de Port-Royal introducen 
la semántica en el dominio de la gramática. El análisis del significado y de las condiciones de verdad persigue la fijación de la unión entre palabras y estados de cosas, de tal manera que la contrastación con el mundo compartido se convierte en la piedra de toque para la verificación de la definición. Por el contrario, el uso pragmático del lenguaje no juega en la Gramática general y razonada ningún papel. La definición sustituye a la narración de ejemplos, en los cuales aparece la palabra, y de este modo se abandona el uso narrativo del lenguaje en favor de la construcción de proposiciones. La narración de la historia será desplazada por la separación entre dos momentos, por un lado el momento del origen del lenguaje, y por otro lado el momento de la construcción de proposiciones. De este modo la pregunta por el origen del lenguaje implica la desconexión respecto de los estadios intermedios en los cuales el lenguaje se desarrolla. En la Minerva, por el contrario, no encontramos ningún planteamiento acerca del origen del lenguaje con anterioridad a la acción de los verbos sobre los nombres fijos. Por el contrario Francisco Sánchez parte del estadio intermedio en el que se produce el lenguaje. El relato mítico de la donación primigenia de nombres a las cosas podría ser entendido como una analogía respecto de la actividad lingüística de narrar. La mayor relevancia del criterio sintáctico en el análisis gramatical ha motivado también la consideración de la Minerva como antecedente de la gramática generativa. No obstante insistiremos en señalar que Francisco Sánchez analiza los principios sintácticos de construcción del lenguaje de manera definitiva en relación a los textos registrados: él no concluye a partir de estos principios ninguna hipótesis acerca de la existencia de una estructura sintáctica innata para el participante de una comunidad lingüística. El concepto de gramaticalidad no se analiza en relación a las capacidades cognitivas, sino en relación a la congruencia entre los documentos escritos ${ }^{x i v}$. No hay en este tratado ninguna consideración de la sintaxis en relación a la subjetividad. Las reglas de la gramática son herramientas para la construcción de un lenguaje exterior, que está disponible ante el lector.

- Por otro lado, los autores de Port-Royal separan claramente la retórica de la gramática. El último capítulo de la Gramática afecta a las figuras de construcción, es decir, a las expresiones anómalas que se alejan de la expresión de la proposición. La base para estas anomalías consiste en que los hombres con frecuencia atienden al sentido de sus pensamientos, en lugar de atender a las palabras. Esta anomalía consiste en modificar el orden correcto de los miembros de la frase a través de la omisión de algunos elementos 
(elipse), la adición de palabras superfluas (pleonasmo) o de la equivocación de la posición de las palabras en la frase (hipérbaton), o la falta de concordancia en número, género y persona (silepsis). Frente a la explicación que Port-Royal ofrece de estos fenómenos por medio del regreso al momento anterior a la ordenación convencional del pensamiento, Francisco Sánchez analiza las figuras retóricas dentro del campo de la gramática. En el cuarto libro de Minerva se ocupa del estudio de las figuras de construcción, las mismas que posteriormente son consideradas por Port-Royal como anomalías. Francisco Sánchez considera como origen de estas figuras la desigualdad entre los elementos de la oración, cuya finalidad es embellecer el lenguaje por medio de la brevedad y la originalidad. Somete estas estrategias estilísticas a los requisitos de la gramaticalidad y del seguimiento de los ejemplos de los textos clásicos. Por ello introduce tras la descripción de la estructura principal de la frase un catálogo de los autores clásicos que han empleado estas figuras. El uso tradicional del lenguaje es tomado como ejemplo del funcionamiento de las reglas sintácticas, como sucede en el caso de su teoría de la elipsis: esta apunta hacia la estructura sintáctica y señala la diferencia entre el orden sintáctico racional y las modificaciones pragmáticas de este orden. Con este enfoque de las figuras retóricas el campo de la gramática queda restringido a sus dimensiones sintáctica y pragmática, considerando el problema del significado como tarea que compete a los filósofos.

\section{Conclusión}

La comparación entre la Minerva o de causis linguae latinae y la Grammaire générale et raisonnée nos muestra la confrontación de dos maneras de entender tanto las relaciones entre lenguaje y pensamiento, como el dominio específico de la gramática. Por un lado, Francisco Sánchez entiende la corrección del lenguaje como la correspondencia entre las estructuras sintácticas y el orden de los acontecimientos narrados, de manera que el lenguaje funciona como reflejo de la historia. Por otro lado, los autores de Port-Royal entienden el lenguaje como una construcción convencional, que permite la fijación de significados universalmente válidos. La desconexión de la referencia respecto del mundo, que se efectúa en la filosofía cartesiana, trae una comprensión del lenguaje como expresión del pensamiento inmediato y con ello la posibilidad de una producción originaria del lenguaje. El resultado de esta operación es la producción de un discurso 
cuya racionalidad reside en la posibilidad de su verificación. La comprensión del tiempo como una sucesión lineal es el resultado de la adecuación del pensamiento a una construcción que pueda ser convencionalmente compartida, y la ruptura de esa posibilidad se refleja en la deformación del lenguaje con la aparición de figuras anómalas. Esta conclusión coincidiría con el planteamiento de Foucault en Las palabras y las cosas. Pero la descripción de la tarea del gramático que puede leerse en Minerva, matiza la tesis de que la compresión del lenguaje hasta la transformación del pensamiento en el siglo XVII sea una forma de "sacralización del texto". Si bien, como hemos visto, el planteamiento del lenguaje en esta obra está ligado a la idea de inspiración bíblica acerca de un lenguaje originario, la señalada diferencia entre la filosofía y la gramática trae una nueva perspectiva en relación a la obra de Francisco Sánchez. De hecho, el gramático no se preocupa ni de la pregunta por el significado ni de la pregunta por las condiciones de verdad del texto: su objetivo es la construcción de un texto gramaticalmente correcto, en el que cada miembro de la frase cumpla su función. El gramático se ocupa de las condiciones previas para el cumplimiento de los criterios de gramaticalidad, a saber, aquella propiedad de la oración que muestra su pertenencia a determinada lengua. De este modo, su trabajo consiste en una permanente investigación de los textos disponibles a la búsqueda de las reglas que en ellos pueda encontrar. La comprensión del lenguaje como una técnica con un funcionamiento autónomo motiva la búsqueda de las condiciones que ha de tener un texto gramaticalmente correcto. Así, la gramática queda acotada como arte o técnica. Su Minerva se encuentra en un período de investigación del lenguaje anterior a la consideración del mismo en relación a la actividad cognitiva de un sujeto.

\footnotetext{
${ }^{i}$ Este trabajo ha sido realizado en el marco de los estudios de máster en Filosofía en la Universidad Humboldt de Berlin. El trabajo fue desarrollado a partir del seminario "From Ideas to Ideology. Port Royal, John Locke, Destutt de Tracy" organizado por Ernst Müller y Stefanie Ertz.

ii Algunos ejemplos de estos estudios se encuentran en la Historia de la Lingüística elaborada por Giulio LEPSCHY: History of Linguistics Volume III: Reinassance and Early Modern Linguistics, New York, Longman, 1998 y en H. PARRET (Ed.) History of linguistic thought and contemporary linguistics, Berlin, Walter de Gruyter, 1976.

iii Bajo el rótulo "lingüística cartesiana" Chomsky se refiere a un período que trasciende el siglo XVII e incluye la concepción del lenguaje de Humboldt y los románticos. Como ha señalado Xavier LABORDA GIL: «El período abarcado por el ensayo de Chomsky es muy amplio y no tan lineal como para que se preste dócilmente a un tratamiento genérico» (La gramática de Port-Royal: fuentes, contenido e interpretación. Capítulo 24: la interpretación chomskiana, 224. Barcelona, Universidad de Barcelona, 1978).
} 
iv Algunos trabajos que relacionan la obra de Francisco Sánchez con la lingüística de Chomsky son: M. BREVA ClaramonTE, «La teoría gramatical del Brocense en los siglos XVII y XVIII» en Revista Española de Lingüistica, $\mathrm{n}^{\circ}$ 10.2, 1980, 351-372 y «Orígenes y evolución de la noción de estructura profunda» en Revista de la Sociedad Española de Lingüística, 1973,1-23; L. A. HERNANDO CUADRADO, «La teoría gramatical en la Minerva del Brocense» en Cuadernos de filología clásica. Estudios latinos. $\mathrm{n}^{\circ} 12$ Servicio de publicaciones Universidad Complutense de Madrid 1997; M. L. HARTO y M. P. GALÁN, «Elipsis, estructura 'profunda' y 'superficial' en el Brocense» en Alcántara: revista del Seminario de Estudios Cacereños, n ${ }^{\circ}$ 29, 1993, 45-60; P. RUIZ PÉREZ, «Las anotaciones del Brocense. Retórica e ideas poéticas renacentistas», en Revista de Filología Hispánica, vol.4, n²2, 1988, 73-98; J. M. NÚÑEZ GONZÁLEZ, «La descripción de los casos latinos por el Brocense: sus presupuestos teóricos» en Minerva: Revista de filología clásica, nº 1, 1987,153-168. La necesidad de la atención a la Minerva dentro exclusivamente del contexto del Renacimiento aparece en trabajos como: S. ARDUINI, «La teoría de la elipsis en Francisco Sánchez de las Brozas: ¿una anticipación de la gramática generativa?» en Anales de Literatura Española I, 1982, 21-54.

v Los autores describen como situación ideal la máxima correspondencia entre letras y sonidos: de manera ideal cada carácter designaría un solo sonido. Sólo se pronunciaría aquello que está escrito.

vi ARNAUld et LANCELOT, Grammaire générale et raisonnée, París, Perlet, 1803. Segunda parte. Capítulo XXIII. Por el contrario, otros pensadores del siglo posterior como Condillac y Vico tomarán los gestos como la primitiva forma de expresión, a partir de los cuales se desarrolla el lenguaje.

vii Así es como lee el autor las palabras del extranjero en el Sofista en relación a la manera en que nombramos en cada ocasión a la misma cosa con muchos nombres: «Hablamos del hombre, y le aplicamos muchos otros nombres. Le atribuimos colores, formas, tamaños, defectos y virtudes. En todos estos casos - y en muchos más- no solo decimos que es hombre, sino también que es bueno e infinitas cosas diferentes. Y del mismo modo procedemos con todas las demás cosas: sostenemos que cada una es una, y, al mismo tiempo, decimos que es múltiple al mencionarla con muchos nombres». (PlATÓN, El Sofista, Madrid, Gredos, Volumen V, 2007, 251 a-b).

viii Esta tesis implica consecuencias sorprendentes desde el punto de vista lingǘstico, como el rechazo de la existencia de "verbos impersonales", de tal manera que en oraciones acerca de fenómenos atmosféricos como por ejemplo "llueve" habría que suponer un sujeto gramatical, en este caso "la lluvia"; como la consideración del infinitivo como la única forma impersonal del verbo o como el rechazo de los modos de los verbos (indicativo, subjuntivo e imperativo) porque o bien sólo introducen una determinación temporal (el futuro, en caso del imperativo) o bien son dependientes del verbo de una oración principal (como en el caso del subjuntivo).

ix De este modo rechaza Francisco Sánchez otras clasificaciones de los gramáticos, que distinguen verbos activos, pasivos, impersonales, deponentes y semideponentes.

x «Un signo es algo que, además de la impresión que hace en los sentidos, suscita en la mente alguna otra cosa» (Agustín De Hipona, De Doctrina Christiana, tomado de ARens H. La Lingüística. Sus textos y su evolución desde la Antigüedad hasta nuestros días. Madrid, Editorial Gredos, 1975, 54). " Car, comme Saint Augustin remarque souvent, l'homme, depuis le péché, s'est accoutumé à ne considérer que les choses corporelles, dont les images entrent par les sens dans notre cerveau, que la plupart croient ne pouvoir concevoir une chose, quand ils ne se la peuvent imaginer, c'est -à-dire se la représenter sous une image corporelle; comme s'il n'y a voit en nous que cette seule manière de penser et de concevoir » (A. ARNAUld y P. NiCOlE, La logique ou l'art de penser París, Gallimard, 1995 Parte I. Capítulo I. 5).

xi Encontraríamos así en la noción de signo dualista de Port Royal un posible precedente de la definición saussuriana del signo como unión de una representación o concepto y una imagen acústica (cfr. F. SAussure, Cours de linguistique générale, París, Grande Bibliothèque Payot, 1997). La primacía otorgada al aspecto fónico del signo material que hemos señalado en la obra de Port Royal se adelantaría así a la concepción de una de las dos caras del signo como "imagen acústica" que leemos en el Curso de lingüística general. A pesar de la pervivencia de esta concepción dualista del signo hemos señalado anteriormente cómo la Gramática de Port Royal carece de las relaciones de oposición y contraste correspondientes al esfuerzo de sistematización propio del estructuralismo del siglo XX.

xii Francisco Sánchez exceptúa aquí los pronombres personales, que como hemos señalado anteriormente son meros sustitutos de los nombres.

xiii «En la concepción cartesiana, dado que la mente puede pensar independientemente de las relaciones con el cuerpo u otras mentes, el lenguaje es tan sólo un vehículo externo para hacer público el propio 
pensamiento privado. Y, dado que el pensamiento es incorpóreo, y el lenguaje corpóreo, el pensamiento debe ser en sí mismo no lingüístico.» (J. PAMPARACUATRO MARTíN, «Aspectos cartesianos de la teoría del lenguaje de Port-Royal» en Éndoxa: Series Filosóficas no 23, 2009, 101-138. Madrid, Universidad Nacional de Educación a Distancia.)

${ }^{\text {xiv }}$ El criterio de racionalidad que justifica la gramaticalidad del texto se debe a la rectitud en el uso de las palabras de acuerdo con los patrones sintácticos, corroborada por los documentos disponibles, pero no a su conformidad con estructuras mentales, al contrario de lo que leemos en varias interpretaciones: «Todo ello ha contribuido a que Francisco Sánchez de las Brozas haya sido calificado por eminentes lingüistas del momento como un adelantado de la gramática filosófica y racional y que sus análisis lingüísticos, fundamentados todos ellos en la consideración del lenguaje como un producto de la mente humana y consiguientemente como algo racional, hayan conseguido el refrendo de autorizados lingüistas como Lakoff y Chomsky» (C. CHAPARRO GÓMEZ, «El Brocense hoy: su vigencia en el ámbito de la filología» en Cuadernos de Filología Clásica. Estudios latinos. 2001, n 21, 177-194). 